\title{
Analytical approaches and methods in quality control procedures of energy food drinks containing caffeine and taurine
}

\author{
Katerina Atanasova Todorova, Ivanka Petkova Pencheva \\ Dept. of Pharmaceutical Chemistry, Faculty of Pharmacy, Medical University - Sofia, Sofia, Bulgaria \\ Email address: \\ katerina_t@abv.bg (K. A. Todorova)
}

\section{To cite this article:}

Katerina Atanasova Todorova, Ivanka Petkova Pencheva. Analytical Approaches and Methods in Quality Control Procedures of Energy Food Drinks Containing Caffeine and Taurine. International Journal of Nutrition and Food Sciences. Special Issue: Taurine and Caffeine Supplementation in Energy Food Drinks: Uses, Side Effects and Quality Control. Vol. 4, No. 1-1, 2015, pp. 1-8. doi: $10.11648 /$ j.ijnfs.s.2015040101.11

\begin{abstract}
Energy food drinks are carbonated drinks that contain large amounts of caffeine and sugar with additional ingredients, such as taurine, amino acids, vitamins and herbal stimulants as guarana. Their popularity among people especially adolescents continues to grow. The success of energy drink is related to their reputation of enhancing physical performances, driving ability when tired, cognitive functions, mental concentration level and reduced the reaction time. The expanded usage of energy food drinks set some problems between producers and consumers. The problems concern quality control questions, limitation of doses of biologically active caffeine and taurine, compatibility of ingredients, side effects. The present literature review analyses and generalized analytical approaches and methods in quality control procedures, their applications, restrictions and priorities.
\end{abstract}

Keywords: Taurine, Energy Drinks, Beverages, Determination

\section{Introduction}

Over the last years, stimulant drinks have developed a considerable share of the global soft drinks market. The consumption of energy drinks has doubled in the last six years (Euromonitor International)

Table 1. Growth of the energy drinks market at world level (2006 - 2011; million litres)

\begin{tabular}{llll}
\hline & $\mathbf{2 0 0 6}$ & $\mathbf{2 0 1 1}$ & \% Growth (2011 vs. 2006) \\
\hline Energy drinks & 2.429 & 3.534 & $+45 \%$ \\
\hline
\end{tabular}

Source: Euromonitor

According to the Zenith International data featured in the annual reports of the British Soft Drinks Association (BSDA), energy drinks consumption in the United Kingdom has grown from 175 million litres in 2000 to 495 million litres in 2011 .

The largest market share in the world have energy drinks Red Bull ${ }^{\mathrm{TM}}$ (40\% of total sales in 2008), Monster ${ }^{\mathrm{TM}}(23 \%)$ and Rockstar $^{\mathrm{TM}}(12,3 \%)$ according to the source Bevnet

Energy drinks often contain ingredients such as caffeine, guarana and especially taurine.

Taurine is one of the most common free amino acids in the human tissue and accounts for up to $0.1 \%$ of total human body weight.It is found in high concentrations in muscle, retina,brain, heart, thrombocytes.It is a major constituent of bile - participates in the conjugation of cholesterol into bile acids to bile salts. Taurine plays an important role in osmoregulation (regulation of pressure in the cells), liver detoxication by binding harmful substances, protects against oxidative stress immune cells, nerve cells, heart, retina, has a positive inotropic effect and the hypocholesterolemic effect, inhibiting platelet aggregation and adhesion, enhances the action of insulin. Taurine increases muscle mass, muscle endurance and strength, maintaining a high concentration of calcium ions and accelerates recovery after exercise. Muscle cells retain more water and thus increase the cell volume. Taurine reduced adipose tissue and reduces body weight.

High concentration of taurine can induce side effectsdeclining heart rates while arterial blood pressure is increased (with caffeine), hypoglycemia, dizziness, diarrhea, peptic ulcer, dehydration, brain and nervous system damage, degrading bipolar disorder. 
The combination taurine with cafeine, amino- acids and guarana in energy drinks increases the risk of side effects. The most risky of them are hypertensive crisis, arrhythmia, dehydration.

This underlined the dangers of uncontrolled abuse of nutritional supplements. A recent government in the U.S. survey indicates that from 2007 to 2011, the number of emergency department (ED) visits related to energy drink consumption nearly doubled, increasing from 10,068 to 20,783 .

In the EU there is no specific legislation about the permissible concentrations of the ingredients for the energy drinks. The European Union has not set an upper limit for example for caffeine, however, if the beverage contains caffeine more than $150 \mathrm{mg} / \mathrm{L}$, the product must be labelled with the term "high caffeine content", in a position close to the name of the food. Furthermore a clear indication of the amount of caffeine per $100 \mathrm{ml}$ in the product must be provided in the label. (Directive 2002/67/EC of the European Commission).

In the United States, energy drink companies have no limitations over the caffeine content of their beverages because the FDA also has placed no restrictions on an upper caffeine limit in these types of beverages.

According to the EFSA ( European Food Safety Authority) opinion of 2009 acceptable daily intake of taurine for a person weighing $60 \mathrm{~kg}$ is respectively $1400 \mathrm{mg}$. The daily maximum level taurine is $3000 \mathrm{mg}$. Surprisingly, most energy drinks contain 1000 miligrams per serving, and some energy drink cans contain more than one serving. With the propagation of energy drinks the normal daily uptake of taurine could easily be exceeded.

So-called energy drinks with very high amounts of taurine (up to $4000 \mathrm{mg} / \mathrm{l}$ are usually granted by certificates of exemption) are increasingly offered on the market.

Table 2. Content of taurine in different energydrinks brands [25]

\begin{tabular}{ll}
\hline Taurine content $(\mathbf{m g} / \mathbf{L})$ & Brand name \\
\hline \multirow{3}{*}{4000} & Battery,Big Energy Shock,Burn,Booster, \\
& Effect,Monster, Red Bull, Tiger,Red \\
& Devil,Shark, Rockstar \\
\hline
\end{tabular}

Table 3. Content of taurine in different energy shots brands [25]

\begin{tabular}{ll}
\hline Taurine content(mg/L) & Brand name \\
\hline 4000 & Burn energy shot,Rockstar energy shot, Shark \\
6666 & energy shot \\
16670 & Red Bull energy shot \\
& Tiger energy shot \\
\hline
\end{tabular}

The present results from analysis indicate that energetic drinks often contain taurine in concentrations quite different (lower or higher) from the declared amounts. Therefore, it is necessary to control the maximum limits of taurine in beverage and food. To control the currently valid maximum limits of taurine in energy drinks a simple, low-cost, fast and rapid analytical methods have to be developed to routinely quality monitoring.

\section{Discussion}

\subsection{Methods for Determination of Taurine in Energy Drinks}

To measure the amount of taurine in energy food drinks and dietary supplements different analytical methods have been developed over the past years.

\subsubsection{Derivatization Reactions}

Taurine is a sulfur-containing $\beta$-amino acid and has not a chromophore group. As taurine does not absorb UV/Vis radiation in significant amounts, a derivatization reaction is needed.

The customary HPLC methods involves pre- or postcolumn derivatization to allow ultraviolet (UV), visible or fluorometric detection.

The required derivatization reagents for precolumn derivatization include (Sanger's reagent, 2,4-dinitrofluorobenzene) [1], 4-fluoro- 7-nitrobenzofurazan (NBD-F) [4], phenylisothiocyanate [23], sulfonyl chloride [23]. As derivatizing reagents also was used o-phthaladehyde and 2-mercaptoethanol [7] other only 0- phthalaldehyde [24]

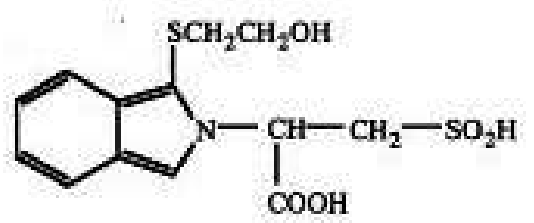

Figure 1. OPA-derivate of taurine shown by Zheng,Lin and Sheng [24]

Sanger's reagent reacts with the amino groups of amino acids in basic solution to form a dinitrophenyl derivative, which has a maximum absorption of around $360 \mathrm{~nm}$. For this reaction to occur, the $\mathrm{pH}$ must be high enough that the amino group is not protonated, but low enough to ensure that the DNFB does not react directly with hydroxide to form 2,4-dinitrophenol. A pH of 9 is suitable for the reaction with taurine [2].

4-fluoro-7-nitrobenzofurazan (NBD-F) acts as a fluorescent reagent that produces the derivative of the primary and secondary amines. These derivatives have a maximum intensity of UV-VIS spectrum near $470 \mathrm{~nm}$ and are fluorescent. Taurine and NBD-F react at equalmolarity. No other peaks that could interfere with the NBD-Taurine peak by $470 \mathrm{~nm}$, so high specification was confirmed. The stability of peak area intensity of NBD-Taurine peak was maintained over 12h [4].

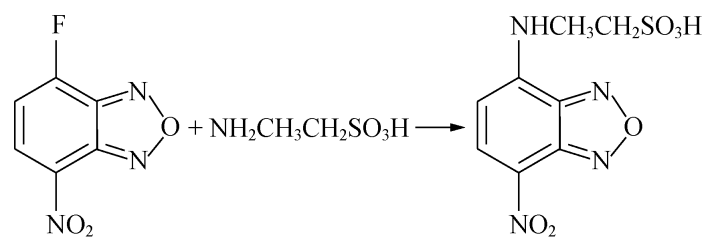

Figure 2. Derivatization of taurine with NBD-F according to the Sawabe and Tagami [4]

There are also UV spectrophotometry methods developed 
for the quantitative and rapid determination of taurine in nutritional supplement drinks using DNP derivative. The methods involve derivatization of taurine by 2,4-dinitrofluorobenzene [3], phenol and sodium hypochlorite [5] and ninhydrin [6].

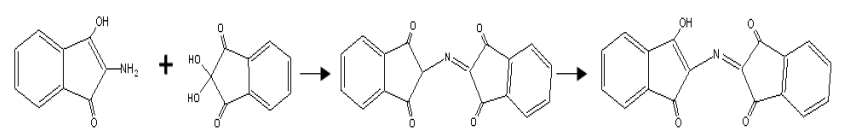

Figure 3. Structure of blue reaction product of taurine and ninhydrin given by Draganov[6]

Ninhydrin reacts with primary and secondary amines producing a blue or purple reaction product (diketohydrindylidene - diketohydrindamine). The intensity of coloring is proportional to concentration of analyzed compounds (first order reaction). After chromatography Vis-absorbance measurement at $525 \mathrm{~nm}$ for taurine after post-chromatographic derivatization with ninhydrin reagent was described. By this method mass confirmation was performed by a single quadrupole MS in negative electrospray ionisation (ESI) scan mode for taurine. [14].

\subsubsection{Capillary Electrophoresis}

A new and very fast method for the quantitative determination of taurine in sports drinks and in beverages by microchip capillary electrophoresis with wavelength-resolved fluorescence detection was developed. As taurine itself is neither fluorescent nor UV-active, it has to be labeled. It is used 4-chloro-7-nitro-1,2,3- benzofurazan (NBD-Cl) as a fluorogenic reagent. The non-fluorescent NBD-Cl binds to amine functions at elevated $\mathrm{pH}$-values and forms the respective NBD-derivatives, which show strong fluorescence. After derivatization with NBD-Cl, the sample is filled into the reservoir of a glass microchip and separated by capillary electrophoresis. 6-aminohexanoic acid was used as an internal standard. The use of the internal standard helps to compensate for fluctuations in the amount of injected sample, in reaction speed during derivatization, in the optical alignment of the detector and in slight changes of migration speed. After dilution, the reaction mixture is directly filled into the sample reservoir of the microchip and injected into the separation channel. The separation is observed with a wavelength-resolved fluorescence detector [8].

\subsubsection{FTIR-Spectroscopy}

FTIR-spectroscopy making it possible to determine the amounts of taurine in energy drinks without any derivatization step or chromatographic separation. The procedure is selective and reproducible and can be treated as reference procedure. FTIR/PLS-spectroscopy leads to reduction of the analysis time compared with chromatographic methods for taurine analysis [9].

\subsection{4. $1 \mathrm{H} \mathrm{NMR}$}

Variation of $\mathrm{pH}$ values revealed the separation of a distinct taurine signal in $1 \mathrm{H} \mathrm{NMR}$ spectra. Taurine concentrations in 20 different energy drinks were analyzed by both using $1 \mathrm{H}$
NMR and LC-UV/vis. The deviation between $1 \mathrm{H}$ NMR and LC-UV/vis results was always below the expanded measurement uncertainty of $12.2 \%$ for the LC-UV/vis method (95\% confidence level) and at worst $10.4 \%$ [10].

\subsubsection{Fluorimetric Determination}

The method is based on the reaction of taurine with tetracyanoethylene to form a highly fluorescent product, which was measured at $\lambda \mathrm{ex} / \mathrm{em}$ of $(360 \mathrm{~nm} / 450 \mathrm{~nm})$ [11].

\subsubsection{Enzymatic Determination}

A successful application of taurine dioxygenase for taurine determination in commercially beverages is described. The gene encoding taurine dioxygenase was cloned from Escherichia coli strain K-12. The taurine dioxygenase enzyme is a Fe (II) / a-ketoglutaric acid-dependent dioxygenase that decomposes taurine as a sulfur source to produce aminoacetaldehyde and sulfite.Enzymatic determination of taurine concentration was carried out based on the measurement of sulfite with Ellman's reagent [21].

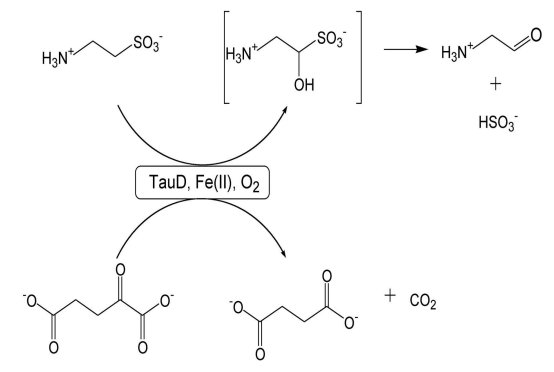

Figure 4. Hydroxylation of taurine from taurine dioxygenase.Mechanism of the reaction shown by Matsuda and Asano [22]

\subsubsection{Chromatographic Methods}

The most common methods for the detection of taurine include high performance liquid chromatography (HPLC) with different detection systems for example UV detection after derivatization [1], [4], [5], [6].

\subsubsection{HILIC Chromatography with ELSD Detector}

ELSD was preferred for taurine determination, as it is generally considered to be a very convenient LC detector for analytes without UV chromophore. This method is simple, low-cost and a large number of samples can be analysed within a short time. The determination does not require any preliminary treatment of the samples except dilution [14].

For the analysis of beverages was used HILIC columns. One benefit is their ability to produce the resolution, efficiency and speed that is associated with the use of sub-2 micron columns on a UHPLC system, without generating high backpressure. HILIC column is used to resolve several beverage components and were selected based on their enhanced performance with polar compounds in comparison to C18. HILIC chromatography was selected because it is suitable for the retention and separation of hydrophilic compounds based on differences in their polarities, whether these analytes are acidic, basic, charged, or neutral.The ELSD allowed for the detection of the non-UV absorbing taurine. [16] [17]. 


\subsubsection{HPTLC - UV-VIS, HPTLC/ESI-MS}

$\mathrm{UV} / \mathrm{Vis}$ absorption spectra obtained after chromatography on silica gel 60 F254 HPTLC plates. Vis-absorbance measurement at $525 \mathrm{~nm}$ for taurine, after post-chromatographic derivatization with ninhydrin reagent.

Taurine was extracted from the plate and after ESI, recorded in the ion mode.Mass confirmation was performed by a single quadrupole MS in negative electrospray ionisation (ESI) scan mode for taurine [15].

\subsubsection{Another Methods}

Electrospray Ionization Mass Spectrometry [12], Thin-layer chromatography (TLC) [18], Liquid chromatography-mass spectrometry [19].

In Eur.Ph are not described methods for determination of taurine.

USP offers analysis of taurine by infrared
absorbtion.Taurine under examination is mixed intimately with potassium bromide. The spectra of the sample and the referent record over the range from about $2.6 \mu \mathrm{m}$ to $15 \mu \mathrm{m}$ $\left(3800 \mathrm{~cm}^{-1}\right.$ to $\left.650 \mathrm{~cm}^{-1}\right)$.

USP analyze chromatographic purity of taurine by Thin-Layer Chromatography. As absorbent is used $0.25-\mathrm{mm}$ layer of chromatographic silica gel mixture. Developing solvent system: a mixture of butyl alcohol, glacial acetic acid, and water (60:20:20). Spray reagent - mixture of butyl alcohol and $2 \mathrm{~N}$ acetic acid (95:5). The plate was allowed to dry for $80^{\circ} \mathrm{C}$ for 30 minutes and then was sprayed with a spray reagent and heated at $80^{\circ} \mathrm{C}$ for about 10 minutes. The plate was examined under white light.

\section{Conditions and Results of the Detection}

\subsection{Derivatization Reactions}

Table 4. Methods with derivatization agents

\begin{tabular}{|c|c|c|}
\hline & Analytical methods & Conditions \\
\hline Ninhydrin [6] & $\begin{array}{l}\text { UV-spectrophoto- metry, } \lambda=570 \mathrm{~nm} \\
{[6]}\end{array}$ & $\begin{array}{l}\text { Solutions containing taurine RS was prepared by dissolving in } 70 \text { vol. } \% \text { ethanol and } \\
\text { was heated with } 0.2 \% \text { solution of ninhydrine for } 20 \mathrm{~min} \text { at } 70{ }^{\circ} \mathrm{C} \text {. } \\
\text { After cooling the prepared solutions were analyzed by normal spectrophotometry in } \\
\text { VIS range at fixed wavelength } 570 \mathrm{~nm} \text { against } 70 \text { vol. \% ethanol matrix as blank } \\
\text { solution [6] }\end{array}$ \\
\hline Phenylisothio-cyanate [23] & $\begin{array}{l}\text { HPLC with UV-VIS detector, } \lambda= \\
254 \mathrm{~nm}[22]\end{array}$ & $\begin{array}{l}\text { HPLC system with a C18 column, mobile phase-sodium acetate buffer } \\
\text { solution-acetonitrile-water [22] }\end{array}$ \\
\hline Sulfonyl chloride [24] & $\begin{array}{l}\text { HPLC with UV-VIS detector, } \lambda=290 \mathrm{n} \\
\mathrm{nm}[23]\end{array}$ & $\begin{array}{l}\text { HPLC C18 reversed phase colum, mobile phase as buffer acetonitrile sodium acetate } \\
(\mathrm{pH}=7.2)[23]\end{array}$ \\
\hline
\end{tabular}

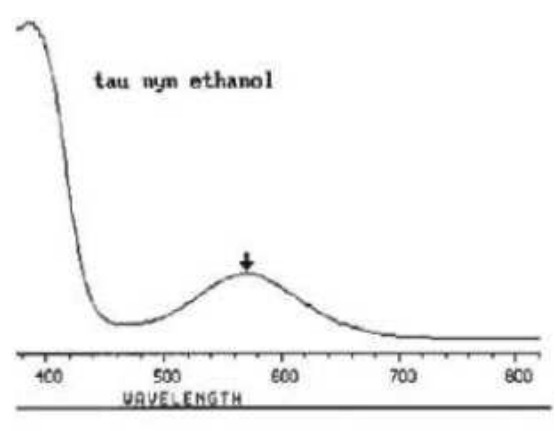

Marked wavelengths

$\operatorname{Reg} \mathrm{A}: \mathrm{L} 570=0.78914$

Figure 5. UV spectra of taurine-ninhydrine color compound in 70 vol. \% ethanol matrix given by Draganov [6]

Analytical methods based on the using of derivatization agents under different conditions are shown on Table 4 and 5 .

\subsection{FTIR-Spectroscopy}

In FTIR spectra the fingerprint region for taurine is between 900 and 1600 . The bands between 1000 and $1100 \mathrm{~cm}^{-1}$ may be explained by the characteristic strong absorption of $=\mathrm{SO}_{2}$. The bands around $1600^{-1}$ may have resulted from $-\mathrm{NH}_{2}$ bending vibrations.

The determination of taurine in energy drinks by FTIR was compared with amino acid analyzer (ion chromatography with ninhydrin-postcolumn derivatization).

The chromatographic analysis of taurine was carried out on an LC 3000 Amino Acid Analyzer.The chromatographic separation was achieved with a cation exchange column BTC $2410-4 \mathrm{~mm}, 125 \times 4 \mathrm{~mm}$ and lithium citrate buffer system. Taurine elution is accomplishedby using a 5 buffer system eluting with increasing $\mathrm{pH}$, starting at $\mathrm{pH} 2.2$ followed by on-line post column reaction with ninhydrin.Identification is performed by two-channel photometric detection at $570 \mathrm{~nm}$ (Channel A) and in case of fault of detection or higher taurine concentration detection on a second channel (Channel B) at $470 \mathrm{~nm}$ is possible. Quantification is carried out with glucosaminic acid as internal standard [9].

\subsection{Enzymatic Determination}

The standard solutions or samples were added to a 96-well microplate containing of reaction solution (100 $\mathrm{mM}$ imidazole buffer [pH 6.9], $2 \mathrm{mM}$ a-ketoglutarate, $2 \mathrm{mM} \mathrm{FeSO} 4$ and taurine dioxygenase). The microplate was incubated at $30^{\circ} \mathrm{C}$ with shaking for $15 \mathrm{~min}$ and $20 \mathrm{ml}$ of $0.5 \mathrm{M}$ ethylenediaminetetraacetic acid (EDTA)-Na was added to stop the reaction. Then, $20 \mathrm{ml}$ of Ellman's reagent [2.5 mM 5,50-dithiobis (2-nitrobenzoic acid)] was added and the microplate was incubated at $30{ }^{\circ} \mathrm{C}$ with shaking for $15 \mathrm{~min}$. The absorbance at $415 \mathrm{~nm}$ was measured by microplate reader [21]. 


\subsection{Chromatographic Methods}

\subsubsection{HILIC Chromatography with ELSD Detector}

A HILIC/UV/ELSD methods has been validated for the simultaneous determination of caffeine and taurine in energy drink [14].

The first method with HPLC system consisted of a Merck-Hitachi model with UV visible HPLC detector set at a wavelength of $272 \mathrm{~nm}$ (maximal absorbance wavelength of caffeine) .The detection of taurine was carried out using an ELSD detector,coupled in-line after the UV detector. Nitrogen was used as the ELSD nebulizer gas ( 3 bars) at a temperature of $40^{\circ} \mathrm{C}$ and the gain was set to 10 . Separation was carried out on an Astec apHeraTM NH2 polymer (150 x $2.1 \mathrm{~mm}$ I.D., $5 \mu \mathrm{m})$. Column temperature was $45^{\circ} \mathrm{C}$. The mobile phase composed of $\mathrm{MeOH} /$ water (30:70, v/v) [13].

The conditions for the second method were : column: Ascentis Express HILIC(Si), $10 \mathrm{~cm}$ x $3.0 \mathrm{~mm}$ I.D., $2.7 \mu \mathrm{m}$ particles mobile phase: (A) $100 \mathrm{mM}$ ammonium acetate, $\mathrm{pH}$ 5.0; (B) water, (C) acetonitrile (9:1:90, A:B:C); flow rate: 0.6 $\mathrm{mL} / \mathrm{min}$; low pressure: $815 \mathrm{psi}$; column temp.: $35^{\circ} \mathrm{C}$. The second method sample was diluted 1:9 in acetonitrile.
Caffeine was detected with UV-detector at $254 \mathrm{~nm}$ and taurine with ELSD detector, $55^{\circ} \mathrm{C}, 3.5$ bar nitrogen [16], [17].

\subsubsection{HPTLC-UV-VIS, HPTLC/ESI-MS}

For taurine analysis the sample was degassed for $20 \mathrm{~min}$ in an ultrasonic bath and diluted with methanol and water 7:3 (v/v). The HPTLC plates were washed (pre-chromatography) with methanol and dried for $15 \mathrm{~min}$ at $120{ }^{\circ} \mathrm{C}$. Chromatography was performed on silica gel 60 F254 HPTLC glass-backed plates and using a mixture of chloroform, ethanol, acetic acid, acetone and water 54:27:10:2:2 (v/v) as mobile phase. As derivatization solution ninhydrin was dissolved in 2-propanol and acetic acid 95:5 (v/v).Then, the plate was dried for $3 \mathrm{~min}$ in a stream of warm air. UV and Vis in situ spectra were recorded using the TLC Scanner and fluorescence spectra in solution using the spectrofluorimeter. Multi-wavelength detection was performed by TLC Scanner.In Vis-absorbance mode taurine was detected at 525 $\mathrm{nm}$, after post-chromatographic derivatization with ninhydrin solution using a TLC Immersion Device and heated on a TLC plate heater for $2 \mathrm{~min}$ at $100{ }^{\circ} \mathrm{C}$. After scanning the plate, the position of each compound was marked.

Table 5. Methods with derivatization agents.

\begin{tabular}{|c|c|c|}
\hline Derivatization agent & Analytical methods & Conditions \\
\hline 2,4-dinitrofluoro-benzene [1] & $\begin{array}{l}\text { HPLC coupled with diode } \\
\text { array detection [1] }\end{array}$ & $\begin{array}{l}\text { Isocratic reverse phase model with aceto- nitrile-phophate solution (pH 7.0) (19: } 81 \text {, } \\
\mathrm{v} / \mathrm{v}) \text { as the mobile phase on a } \mathrm{C} 18 \text { column [1] }\end{array}$ \\
\hline 2,4-dinitrofluoro-Benzene [2] & $\begin{array}{l}\text { HPLC with UV- detection } \lambda= \\
360 \mathrm{~nm} \text {, the peak } \\
\text { absorbance for the taurine } \\
\text { derivative [2] }\end{array}$ & $\begin{array}{l}\text { Reversed phase column with a } 2.1-\mu \mathrm{m} \text { particle size and column dimensions of } 4.6 \mathrm{~mm} \\
\mathrm{x} 50 \mathrm{~mm} \text {,an isocratic elution of } 80: 20(\mathrm{v} / \mathrm{v}) \text { of the phosphate buffer/acetonitrile. } \\
\text { The derivatization procedure- into a test tube were pipeted a part of sample,carbonate } \\
\text { buffer,methyl sulfoxide (DMSO) and } 2,4-\text { dinitrofluorobenzene (DNFB). The solution } \\
\text { was shaken for } 30 \mathrm{~s} \text { and placed in a } 40^{\circ} \mathrm{C} \text { water bath for } 15 \mathrm{~min} \text {. At the end of the } 15 \\
\text { min, } 6.5 \mathrm{~mL} \text { of the phosphate buffer was added to the mixture [2] }\end{array}$ \\
\hline 2,4-dinitrofluoro-Benzene [3] & $\begin{array}{l}\text { UV - spectrophotometry } \\
\text { The absorption spectrum of } \\
\text { the DNP - taurine showed the } \\
\text { maximum absorption } \\
\text { wavelength at } 358 \mathrm{~nm}[3]\end{array}$ & The DNP-taurine was extracted by chloroform, and measured [3] \\
\hline 4-fluoro-7-nitro-benzofurazan [4] & $\begin{array}{l}\text { HPLC with UV-VIS detector } \\
\text { The NBD-Taurine derivative } \\
\text { was determined at } 470 \mathrm{~nm} \mathrm{[4]}\end{array}$ & $\begin{array}{l}\text { The best conditions for the reaction were } \mathrm{pH} 9.0 \text {, temperature } 60{ }^{\circ} \mathrm{C} \text { and reaction time } \\
10 \text { min on the basis of the peak area intensity of labeled taurine(NBD-Taurine).HPLC } \\
\text { using a conventional Octadecyl silane (ODS) column. A mixture of disodium } \\
\text { hydrogenphosphate-citric acid buffer solution ( } \mathrm{pH} 5.4 \text { ) containing } \\
\text { tetrabutylammonium bromide and acetonitrile ( } 7: 3 \text { ) was used as the mobile phase. } \\
\text { The column temperature was } 40{ }^{\circ} \mathrm{C} \text { Because the derivative was retained on a } \\
\text { conventional ODS column using tetrabutylammonium bromide as the counter ion, an } \\
\text { expensive ion-exchange column was not necessary. [4] }\end{array}$ \\
\hline $\begin{array}{l}\text { Phenol and sodium hypochlorite } \\
\text { [5] }\end{array}$ & $\begin{array}{l}\text { UV }- \text { spectrophotometry } \lambda= \\
630 \mathrm{~nm} \text {, the peak absorbance } \\
\text { for the taurine derivative [5] }\end{array}$ & $\begin{array}{l}\text { The conditions for the reaction - room temperature and } \mathrm{pH} 10.35 \text {. Ion exchange was } \\
\text { used to improve the selectivity [5] }\end{array}$ \\
\hline
\end{tabular}

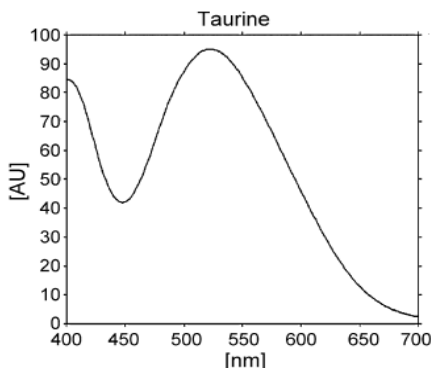

Figure 6. UV/Vis absorption spectra obtained after chromatography on silica gel 60 F254 HPTLC plates posted by Aranda and Morlock [15]
Using a HPLC pump the HPTLC plate was connected to the VG platform II single-quadrupole mass spectrometer.The compounds were eluted from the layer with a mixture of methanol and formate buffer ( $\mathrm{pH} 4.0)$ 95:5 (v/v) .

The MS system was operated in the scan mode with the following parameters for ESI- : source temperature $120{ }^{\circ} \mathrm{C}$, capillary voltage $-3.5 \mathrm{kV}, \mathrm{HVl}$ ens $0.5 \mathrm{kV}$, cone voltage- $55 \mathrm{~V}$, dwell time $0.5 \mathrm{~s}$, inter channel delay 0.02 , repeats 1 , span 0.5.Taurine was extracted from the plate and after ESI, recorded in the positive and negative ion mode.The ESI- mass spectra of taurine the $[\mathrm{M}-\mathrm{H}]-$ ion were detected at $\mathrm{m} / \mathrm{z} 124$ [15]. 


\subsubsection{Electrospray Ionization Mass Spectrometry}

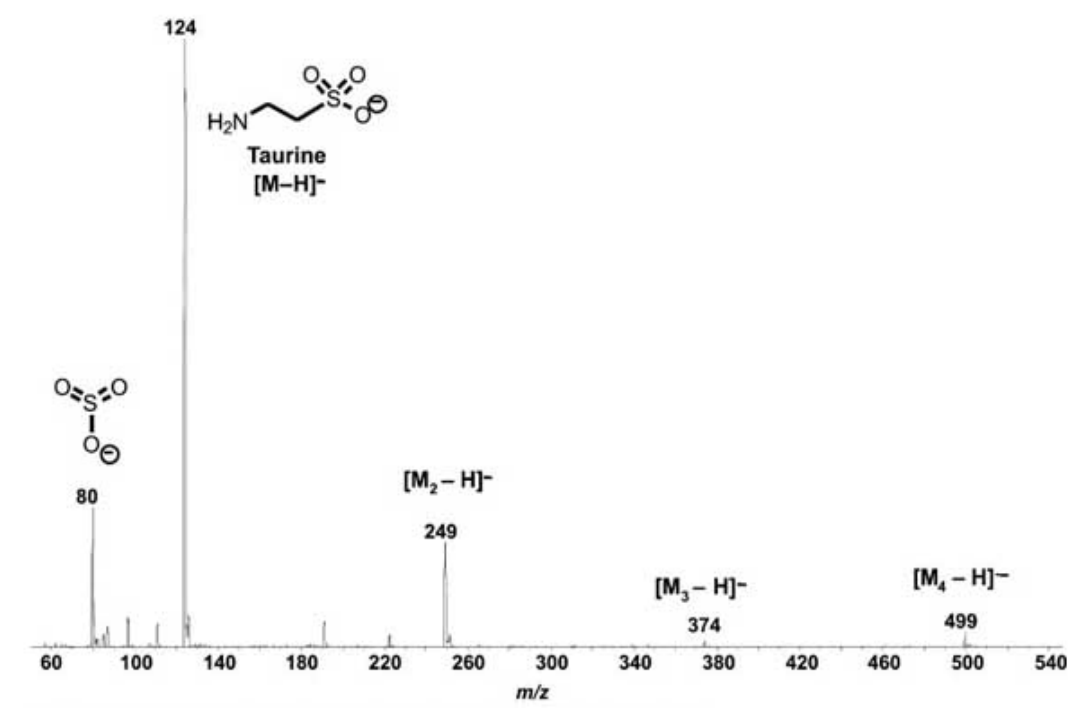

Figure 7. The ESI(-)-MS spectra of pure taurine from the analysis of Catharino and Haddad [12]

After the homogenization, the solutions were first filtrated two times with a common filter paper and next with a Durapore membrane (Millipore) with $0.45 \mu \mathrm{m}$ size pores. The samples were automated injected into the ESI source of the mass spectrometer $(10 \mu \mathrm{L})$ by using a HPLC system. The best mode of ion detection for taurine was the negative ion mode. The major conditions were as follows: scan range, $m / z$ 50-200; heater temperature, $100{ }^{\circ} \mathrm{C}$; flow of the nitrogen carrier gas, 20 $\mathrm{L}$ min $^{-1}$; sheath gas, $0.0 \mathrm{~L} \mathrm{~min}^{-1}$; curtain gas, $20 \mathrm{~L} \mathrm{~min}^{-1}$; nebulizer potential, $-3500 \mathrm{~V}$; declustering potential, $-46 \mathrm{~V}$; and entrance potential, $-7 \mathrm{~V}$. Taurine was eluted by an isocratic elution system using a 1:1 methanol/water solution.The
ESI(-)-MS of pure taurine shows mainly the deprotonated molecule [M - H] $]^{-}$of $\mathrm{m} / \mathrm{z} 124$ as well as the dimer of $\mathrm{m} / \mathrm{z} 249$, the trimer of $\mathrm{m} / \mathrm{z} 374$ and the tetramer of $\mathrm{m} / \mathrm{z} 499$. The ion of $m / z \quad 80$ was attributed to $\mathrm{SO}_{3}^{-}$formed via in-source collision-induced dissociation of $[\mathrm{M}-\mathrm{H}]^{-}[12]$.

The direct injection ESI(-)-MS/MS method allows rapid determination of taurine with a total analysis time of $c a .2 \mathrm{~min}$. False positives are minimized through the use of SRM via the transition $\mathrm{m} / \mathrm{z} 124 \rightarrow \mathrm{m} / \mathrm{z}$ 80. The tandem mass spectrometric (MS/MS) experiments were performed using single reaction monitoring (SRM) for the dissociation of the precursor ion of $\mathrm{m} / \mathrm{z} 124$ to its most abundant fragment ion of $\mathrm{m} / \mathrm{z} 80$ [12].

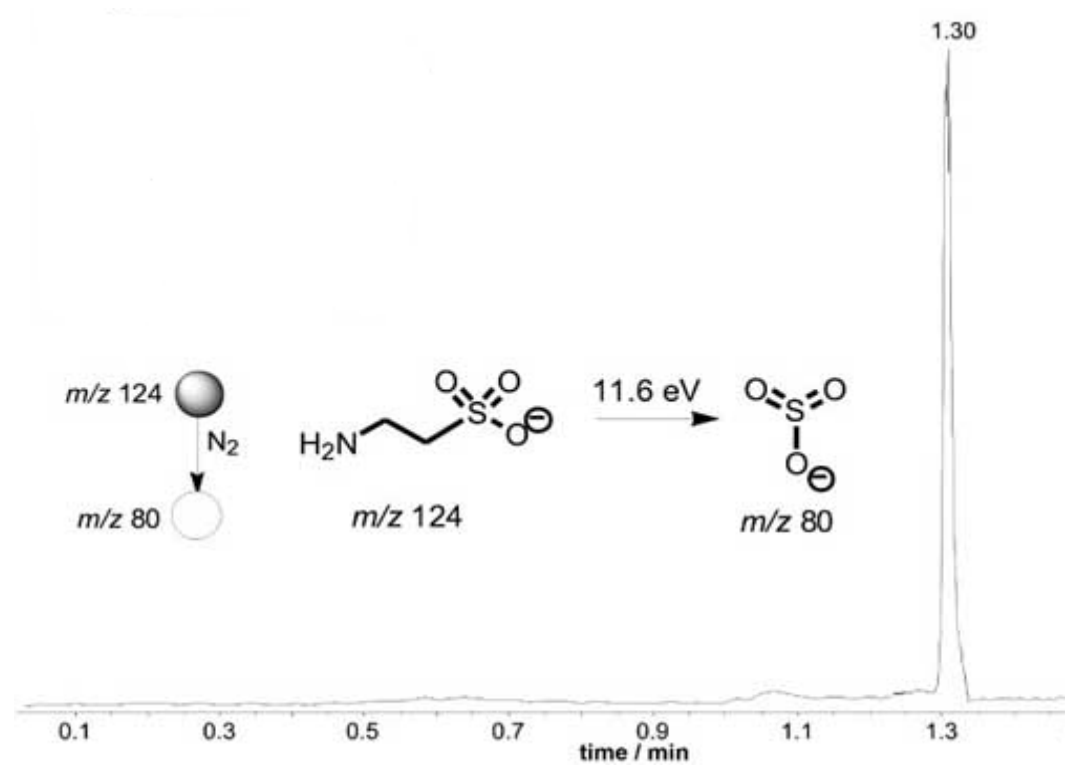

Figure 8. Chromatogram using SRM $\mathrm{m} / \mathrm{z} 124 \rightarrow \mathrm{m} / \mathrm{z} 80$ showing the detection of taurine after 1.3 min of sample injection from the analysis of Catharino and Haddad [12]

\subsubsection{Thin-Layer Chromatography}

The content of taurine was measured by TLC. TLC method with the mixture of propanol-water-glacial acetic acid-ethanol $(5.2: 2: 2: 0,8)$ as the developing agent and $1 \%$ ninhydrin in ethanol as the chromogenic agent [18]. 


\subsubsection{Liquid Chromatography-Mass Spectrometry}

A procedure based on liquid chromatography -mass spectrometry (LC-MS) is described for determination of taurine in different dietary supplements. After addition of tryptophan as internal standard, both solid and liquid specimens were extracted with hexane / isopropanol (9:1). Chromatography was performed on a $\mathrm{C}_{18}$ reversed-phase column using water/methanol/ acetic acid (75:20:5, v/v/v) as a mobile phase. Analytes were determined in LC-MS single ion monitoring mode with atmospheric pressure ionization-electrospray (ESI) interface [19].

\subsubsection{Electrophoresis}

The separation of caffeine and taurine was performed using the Micellar electrokinetic chromatography ( MEKC) technique in a short $10.5 \mathrm{~cm}$ capillary with the composition 40 mM CHES, $15 \mathrm{mM} \mathrm{NaOH}$, and $50 \mathrm{mM}$ SDS, pH 9.36.Under these conditions, the migration time of caffeine is $43 \mathrm{~s}$ and of taurine $60 \mathrm{~s}$. The substances are detected using a contactless conductometry / ultraviolet (UV) photometry detector that enables recording both signals at one place in the capillary [20].

\section{Detection Limits}

Detection limits of different methods are shown in table 6.

\section{Conclusions}

Different methods for analysis of taurine in energy drinks, food, dietary supplements were reported.The developed methods are associated with the need to control the content of taurine in the beverages because of their increased use and risk of side effects. The analyses needs to be rapid, specific, inexpensive and easily reproducible.

Table 6. Detection limits of different methods

\begin{tabular}{lll}
\hline Method & LOD & LOQ \\
\hline $\begin{array}{l}\text { UV-spectrophotometry after } \\
\text { derivatization reaction with } \\
\text { ninhydrin [6] }\end{array}$ & $140 \mathrm{mg}$ & $1400 \mathrm{mg}$ \\
$\begin{array}{l}\text { Electrospray Ionization Mass } \\
\text { Spectrometry [12] }\end{array}$ & $0.03 \mathrm{mg} \mathrm{mL}-1$ & $0.1 \mathrm{mg} \mathrm{mL}-1$ \\
$\begin{array}{l}\text { HILIC chromatographywith } \\
\text { UV/ELSD detector [15] }\end{array}$ & $2 \mathrm{mg} . \mathrm{L}-1$ & $5 \mathrm{mg} . \mathrm{L}-1$ \\
MEKC [20] & $24 \mathrm{mg} / \mathrm{L}$ & \\
\hline
\end{tabular}

\section{References}

[1] Hongyuan Yan, Fengxia Qiao, Minglei Tian , Kyung Ho Row, Application of 2,4-dinitrofluorobenzene pre-column derivatization to quantitative determination of taurine and its intermediate in beverages and milk samples,Journal of Liquid Chromatography \& Related Technologies, Volume 36, Issue 1, pages 35-43, 2012.

[2] Brad McConn, Determination of taurine in energy drinks by high-performance liquid chromatography, Concordia College Journal of Analytical Chemistry 3, pages 47-52, 2012.
[3] H. Soga, M. Aono, A spectrophotometric method for the determination of taurine in nutritional supplement drinks, Food and Agriculture Organization of the umited Nations, 1957.

[4] Yoshiyuki Sawabe, Takaomi Tagami, Katsuhiro Yamasaki, Determination of Taurine in Energy Drinks by HPLC Using a Pre-column Derivative, Journal of Health Science 54 (6), pages 661-664, 2008.

[5] Oi-Wah Lau , Shiu-Fai Luk и Teresa PY Chiu, Spectrophotometric determination of taurine in food samples with phenol and sodium hypochlorite as reagents and an ion-exchange clean-up, Analyst Issue 5, pages 653-655, 1990

[6] Georgi B. Draganov, UV-spectrophotometry determination of taurine in energy drink mixtures, International Journal of Nutrition and Food Sciences,Vol. 3, No. 2, pp. 123-126, 2014.

[7] Koichi Saito, Masakazu Horie, Yoshikazu Tokumaru, Hiroyuki Nakazawa, Determination of Taurine in Foods by HPLC with On-Column Fluorescence Derivatization, Food Hygiene and Safety Science, Vol.38, No.6, page 400, 1997.

[8] Sebastian Götz, Tobias Revermann, Uwe Karst, Quantitative on-chip determination of taurine in energy and sports drinks, Lab on a Chip, Issue 1, pages 93-97, 2007.

[9] S. Triebel, C. Sproll,H. Reusch, R. Godelmann, D. W. Lachenmeier, Rapid analysis of taurine in energy drinks using amino acid analyzer and Fourier transform infrared (FTIR) spectroscopy as basis for toxicological evaluation,Amino Acids, Vol. 33, Issue 3,pages 451-457, 2007.

[10] Monika Hohmann, Christine Felbinger, Norbert Christoph, Helmut Wachter, Johannes Wiest,Ulrike Holzgrabe, Quantification of taurine in energy drinks using $1 \mathrm{H}$ NMR, Journal of Pharmaceutical and Biomedical Analysis, Vol. 93, pages 156-160, 2014.

[11] M. K. Sharaf El Din and M. E. K. Wahba, Novel validated spectrofluorimetric methods for the determination of taurine in energy drinks, The Journal of Biological and Chemical Luminescence, 2014.

[12] Rodrigo R.Catharino,Renato Haddad, Helena T. Godoy,Marcos N. Eberlin,Leonardo S. Santos, Fast Analysis of Taurine in Energetic Drinks by Electrospray Ionization Mass Spectrometry,Journal of the Brazilian Chemical Society, vol.22, No.4, pages 801-806, 2011.

[13] Raluca-Ioana Chirita, Catalina Dascalu, Lucian Gavrila, Claire Elfakir,Simultaneous Analysis of Taurine and Caffeine in Energy Drinks using Hydrophilic Interaction Chromatography with UV and Evaporative Light Scattering Detection, Revista de Chemie-Bucharest original edition,pages 1173-1176, 2010.

[14] Aranda M, Morlock G.,Simultaneous determination of riboflavin, pyridoxine, nicotinamide, caffeine and taurine in energy drinks by planar chromatography-multiple detection with confirmation by electrospray ionization mass spectrometry, Journal of Chromatography A,Vol. 1131, Issues 1-2, Pages 253-260, 2006.

[15] Mario Aranda, Gertrud Morlock, Simultaneous determination of riboflavin, pyridoxine, nicotinamide, caffeine and taurine in energy drinks by planar chromatography-multiple detection with confirmation by electrospray ionization mass spectrometry, Journal of Chromatography A, Vol. 1131, Issues 1-2, Pages 253-260, 2006. 
8 Katerina Atanasova Todorova and Ivanka Petkova Pencheva: Analytical Approaches and Methods in Quality Control Procedures of Energy Food Drinks Containing Caffeine and Taurine

[16] Olga Shimelis, Hugh Cramer, and Michael D. Buchanan, Determination of Additives in Beverages Using Ascentis Express Columns,US Reporter, Vol. 30.3, pages 20-21.

[17] HPLC Analysis of Sugars and Taurine in an Energy Drink on Ascentis ${ }^{\circledR}$ HILIC using UV and ELSD Detection in Series, Journal of Pharmaceutical and Biomedical Analysis 51, pages 131-137, 2010.

[18] Hui Qiu-sha, Determination of Taurine in Health Drinks by TLC, Journal Food and Drug, 2011.

[19] Emilia Marchei,Manuela Pellegrini,Roberta Pacifici,Ilaria Palmi,Simona Pichini,Development and validation of a high-performance liquid chromatography-mass spectrometry assay for methylxanthines and taurine in dietary supplements,Journal of Pharmaceutical and Biomedical Analysis,Vol. 37, Issue 3, Pages 499-507, 2005.

[20] Blanka Vochyanova, Frantisek Opekar, P.Tuma, Simultaneous and rapid determination of caffeine and taurine in energy drinks by MEKC in a short capillary with dual contactless conductivity / photometry detection, Electrophoresis, Vol.35, Issue11, pages $1660-1665,2013$.
[21] Motoki Matsuda, Yasuhisa Asano, A simple assay of taurine concentrations in food and biological samples using taurine dioxygenase, Analytical Biochemistry Vol. 427, Issue 2 pages 121-123, 2012.

[22] Shi Yan, Song Guangxi, Xiong Jing, Wei Feng, Ma Shuangcheng, Lin Ruichao, Determination of Taurine in Heath Food by RP-HPLC with Precolumn Phenylisothiocyanate Derivatization, Chinese Pharmaceutical Affairs, Issue 2, pages 144-146, 2012.

[23] Zhu Hui, Zhao Zhi-Hong, SHI Wen-Rong, Determination of Taurine in Food by Pre-column HPLC with Sulfonyl Chloride,Food science,Vol.21,Issue 12, pages 116-118, 2000.

[24] Zheng G, Lin S., Wei Sheng Yan Jiu, Determination of taurine in foods by high performance liquid chromatography, Journal of Hygiene Research,Vol.27, Issue 4, pages 266-268, 1998.

[25] Silvia Zucconi, Chiara Volpato, Felice Adinolfi, Evita Gandini,Enrica Gentile, Alberico Loi, Linda Fioriti, External scientific report, Gathering consumption data on specific consumer groups of energy drinks, Supporting Publications 2013:EN-394. 